\title{
Dysregulation of GPCR Signaling in Cardiovascular Diseases: A Potential Role for Exercise Training?
}

\author{
Kwang-Seok Hong ${ }^{1}$, Sukho Lee ${ }^{2}$ \\ ${ }^{1}$ Robert M. Berne Cardiovascular Research Center, University of Virginia-School of Medicine, Charlottesville, VA, USA; \\ 2Department of Counseling, Health, and Kinesiology, College of Education and Human Development, Texas A\&M University-San Antonio, \\ San Antonio, TX, USA
}

\begin{abstract}
PURPOSE: The superfamily of G protein-coupled receptors (GPCR) are activated by biological molecules (e.g. neurotransmitters) and are involved in many physiological events. As exaggerated GPCR-mediated signaling may contribute to cardiovascular disorders, RGS proteins (regulators of G-protein signaling) are viewed as an important regulatory molecule for the negative modulation of this signaling pathway. To address the significance of RGS proteins and suggest potential effects of exercise training on this molecule, a literature review on RGS proteins was conducted.
\end{abstract}

METHODS: A systemic search in PUBMED was performed to obtain previous studies investigating roles of RGS proteins in the cardiovascular systems.

RESULTS: RGS proteins directly bind to the $\mathrm{G}_{\alpha}$ subunit of heterotrimeric $\mathrm{G}$ proteins to inhibit GPCR signaling pathways and terminate their activity. Using mice genetically lacking RGS2 and RGS5, these proteins have been shown to contribute to pressure overloadinduced cardiac remodeling. Further, it has been suggested that systemic knockout of RGS2 protein causes hypertension by potentiating $\mathrm{G}$ protein signaling-mediated vascular responses and impairing nitric oxide/cGMP-induced vasorelaxation. Thus, RGS proteins have been suggested as potential drug targets for cardiovascular disorders accompanied by dysregulation of RGS proteins and GPCR signaling. Although exercise training has also been well-documented to strengthen cardiovascular function and ameliorate circulatory diseases, cellular mechanisms underlying the contribution of exercise intervention to RGS-mediated GPCR signaling have not been explored.

CONCLUSIONS: This brief review discusses roles played by RGS proteins in the cardiovascular system and suggests future studies for investigating the interaction between exercise training and RGS protein-mediated regulation of GPCR signaling.

Key words: G protein-coupled receptors, Negative feedback regulation, Exercise training, Cardiovascular system

\section{INTRODUCTION}

The largest group of transmembrane receptors is the superfamily of $\mathrm{G}$ protein-coupled receptors (GPCRs) [1]. These receptors are involved in numerous physiological events and represent the class of proteins most often targeted for pharmaceutical interventions [2,3]. It has been demonstrated that GPCRs play a crucial role in cardiovascular homeostasis under physiological and pathological circumstances $[4,5]$. Exaggerated activation of GPCRs including adrenergic receptors, angiotensin II recep- tors, or endothelin receptors ubiquitously expressed in vascular smooth muscle cells (VSMCs) or cardiac muscle results in hypertension or heart failure [6]. Hyper-contractility of VSMCs or cardiomyocytes by GPCR ligands (e.g. norepinephrine, angiotensin II), a major hallmark of cardiovascular disorder, causes blood pressure elevation and ventricular hypertrophy [7]. Given their importance in cell signaling, the activation of GPCR and subsequent intracellular signaling events are likely to be tightly regulated to ensure appropriate cellular function. Considerable progress in the understanding of regulators of G protein signaling (RGS)

Corresponding author: Sukho Lee Tel +1-210-784-2537 Fax +1-210-784-2559 E-mail sleedatamusa.edu

Received 22 Jun 2017 Revised 17 Jul 2017 Accepted 14 Aug 2017

(a) This is an Open Access article distributed under the terms of the Creative Commons Attribution Non-Commercial License (http://creativecommons.org/licenses/by-nc/4.0/) which permits unrestricted non-commercial use, distribution, and reproduction in any medium, provided the original work is properly cited. 
proteins has occurred during the last decade and the proteins have been reported to modulate GPCR-mediated signaling. Impaired regulation of GPCR signaling cascades is likely coupled to many cardiovascular disorders. It has been demonstrated that altered expression or dysfunction of RGS proteins results in hypertension and cardiac hypertrophy [8]. However, potential role of exercise intervention on RGS protein-mediated regulation of GPCR signaling has not been investigated. In this review, we will describe 1) characteristics of RGS protein, discuss 2) the role of RGS proteins in the cardiovascular system, and propose 3) potential impact of exercise intervention on RGS protein regulation.

\section{CHARACTERISTICS OF RGS PROTEINS}

\section{RGS proteins as GTPase-activating proteins}

GPCR coupled heterotrimeric G proteins are comprised of $\alpha, \beta$, and $\gamma$ subunits and function as signal transducers. The trimeric $G$ protein family is categorized into four classes based on the structure and function of the a subunit: 1) $\mathrm{G}_{\mathrm{as}}$ or 2) $\mathrm{G}_{\mathrm{ai} / \mathrm{o}}$ protein activate or inhibit adenylyl cyclase respectively, 3) $\mathrm{G}_{\alpha \mathrm{q}}$ protein stimulates various isoforms of phospholipase C (PLC) and in turn generates diacylglycerol (DAG) and inositol trisphosphate $\left(\mathrm{IP}_{3}\right)$ by cleaving phosphatidylinositol bisphosphate $\left(\mathrm{PIP}_{2}\right)$, and 4) $\mathrm{G}_{\mathrm{\alpha} 12 / 13}$ protein activates Rho GTPase. Ligand binding to an appropriate GPCR promotes exchange of GDP to GTP on the a subunit. The GTP-bound a subunit dissociates from $\beta$ and $\gamma$ subunit complexes and participates in downstream signaling cascades [9]. The magnitude

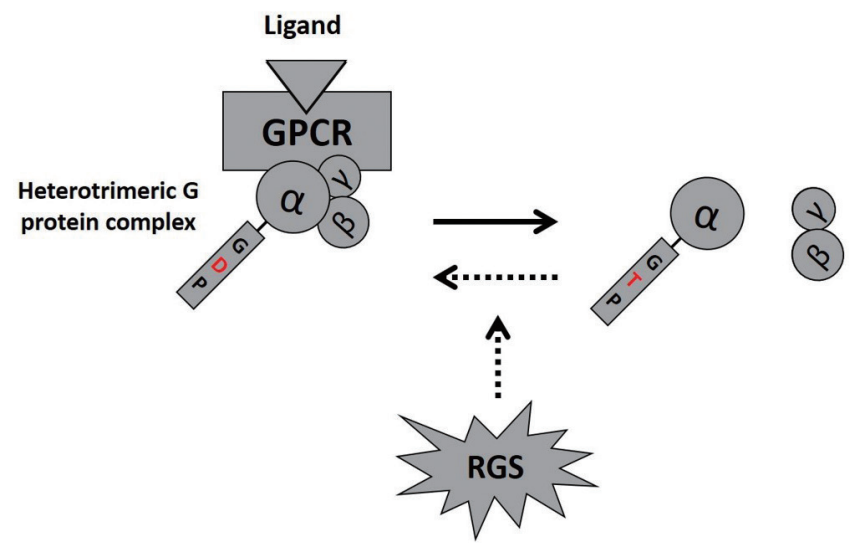

Fig. 1. RGS protein-mediated modulation of GPCR signaling. Ligand activation of GPCRs allows the $G_{\alpha}$ subunit to dissociate from the $G_{\beta \gamma}$ subunits (rightwards arrow). RGS proteins substantially accelerate the activity of the intrinsic GTPase within the $G_{a}$ subunit and in turn leads $G_{a}$ subunit to reassociate with the $G_{\beta \gamma}$ subunits (leftwards arrow). GTP, guanosine trisphosphate; GDP, guanosine diphosphate. and/or duration of the signaling is determined by how long the Ga subunit is activated, which is determined by the intrinsic GTPase activity of the a subunit. GTP hydrolysis by the intrinsic GTPase results in a conformational change of the a subunit, allowing re-association of GDPbound inactive a subunit with the $\beta$ and $\gamma$ subunit complexes. Thus the intracellular signaling response is terminated (Fig. 1). However, as the rate of intrinsic GTPase is relatively slow, a GTPase activating protein (GAP) is necessary for effective termination of G protein-mediated signaling. It is well accepted that RGS proteins serve as GAPs and fine-tune the GPCR activities by accelerating the GPTase activity up to 2,000 times [10]. Thus, GPCR-mediated signaling is controlled by regulating the rapid 'on'-'off' kinetics of downstream effectors and diminishing sensitivity of GPCR [11].

To date, more than 30 RGS proteins have been identified and classified based on their sequence homology and additional domains [12]. Of particular relevance, the RGS protein subfamily, B/R4, consisting of RGS1, 2, 3, 4, 5, 8, 13, 16, 18, and 21 proteins [13] is highly expressed in cardiovascular tissues [14]. Notably, RGS2, 4, and 5 proteins are widely distributed in heart and blood vessels and genes for the three proteins are located on the same chromosome and associated with blood pressure homeostasis [11]. The structure of B/R4 RGS proteins are commonly characterized by a core RGS carboxyl-terminal domain referred to as the 'RGS box' (Fig. 2). This region of the protein is composed of approximately 120 amino acids conferring the catalytic function of the RGS protein. Once GPCRs are activated, RGS proteins distributed in cytosol are

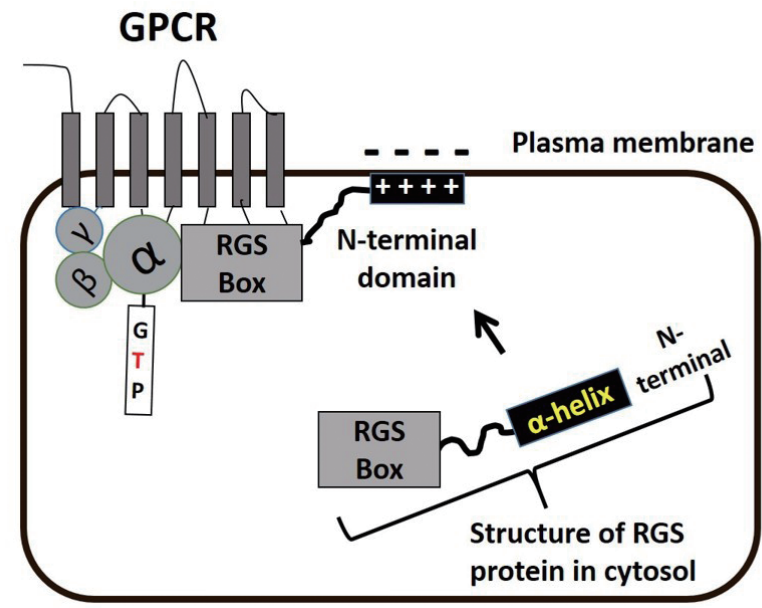

Fig. 2. Schematic diagram showing the interaction of RGS proteins with $G$ protein subunits. Once GPCRs are activated, RGS proteins bind to the plasma membrane through an $\mathrm{N}$-terminal amphipathoc helix of the regulatory protein. The RGS box directly interacts with active $G_{\alpha}$ subunit and in turn facilitates GTP hydrolysis on the subnit. GTP, guanosine trisphosphate. 
translocated towards to GPCRs on the plasma membrane. The RGS box directly interacts with $\mathrm{G}_{a}$ protein of the GPCR, regulating GTPase activity and modulating G protein-dependent intracellular signaling (Fig. 2). While the N-terminal domain (33 amino acids) of RGS proteins does not take part in the acceleration of GTPase, the amphipathic a helical structures of this domain provide sites for interaction with the plasma membrane [15,16] (Fig. 2). However, only RGS3 protein interestingly has PDZ (PSD95/Dlg/Z0-1/2)-PEST (proline, glutamin, serine, threoninerich)-acidic N-terminal domain, instead of the amphipathic a helical structure shown in other B/R4 RGS proteins [13].

\section{Selective regulation of RGS proteins}

RGS proteins appear to have functional similarity for the modulation of GPCR activity in the cardiovascular system. It has been suggested that individual RGS proteins of the B/R4 subfamily indiscriminately interacts with $G_{a i}$ or $G_{a q / 11}$ protein [9]. However, since a variety of GPCRs and RGS proteins are not evenly expressed in all cells or tissues, it has been recently considered that RGS proteins may differentially interact with specific GPCRs. Therefore, numerous investigations have tested the hypothesis that RGS proteins preferentially and precisely discriminate specific GPCR bound to the same Ga protein [17].

Studies have demonstrated that RGS3 protein selectively inhibits endothelin-1 receptor-mediated signaling while RGS1 and 2 proteins show negligible inhibitory effects on the endothelin-1 receptor signaling pathways [18]. In that study, substantial attenuation of angiotensin II type 1 receptor $\left(\mathrm{AT}_{1} \mathrm{R}\right)$-dependent signaling is observed in a manner dependent on RGS2 and 3 proteins, but not RGS4 protein. Additionally, RGS4 protein efficiently attenuates $\mathrm{Ca}^{2+}$ signaling in response to activation of cholinergic receptors in pancreatic acinar cells [19]. In particular, cholinergic receptors are preferentially regulated by RGS4 protein. In glomerular mesangial cells, urotensin II-mediated elevation in intracellular global $\mathrm{Ca}^{2+}$ levels is specifically modulated by RGS2 protein [20]. In vascular smooth muscle cells (VSMCs), RGS3 or 5 protein is involved in selectively control of signaling of the acetylcholine receptor or AT1R, respectively [21]. With respect to B/R4 RGS proteins outside of the cardiovascular system, RGS8 and 16 proteins have been reported to selectively interact with M1 muscarinic receptor expressed in xenopus oocytes or alpha2-adrenergic receptor in COS-7 fibroblast-like cell line, respectively $[22,23]$. CXCL12 (chemokine protein) and adenosine-activated GPCR signaling is regulated by RGS13 in human mast cells [24]. While RGS18 and 21 proteins predominantly expressed in osteoclasts [25] and taste bud cells [26], respectively, regulate $\mathrm{G}_{\alpha \mathrm{q}} \mathrm{PCR}$, their specific selectivity has not been fully delineated. General characteristics of B/R4 RGS proteins are summarized in Table $1[13,17]$.

The N-terminal domain of RGS proteins provides specificity of the RGS protein. The ability of RGS4 protein, deleted of its N-terminal domain, to inhibit $\mathrm{G}_{\mathrm{aq}}$ protein-induced $\mathrm{Ca}^{2+}$ signaling is approximately 10,000 times less than the full-length RGS4 protein [27]. Similarly, Nterminal mutation decreases the inhibitory effects of RGS5 protein on $\mathrm{Ca}^{2+}$ signaling in response to application of Ang II and endothelin-1. Further, the N-terminal-deleted RGS5 protein is largely confined to the cytosol despite agonist stimulation [28]. Moreover, the same research group has compared abilities of RGS2, 4, and 5 proteins to regulate $\mathrm{AT}_{1} \mathrm{R}$-mediated $\mathrm{Ca}^{2+}$ signaling [29]. As a consequence, it has been found that inhibition of $\mathrm{Ca}^{2+}$ signaling is dependent on the total volume of RGS proteins transfected to HEK-293 cells. Among three RGS proteins, RGS2 protein is a potent modulator for $\mathrm{AT}_{1} \mathrm{R}$ signaling. Notably, switching of the N-terminal domain between RGS2 and 5 proteins dramatically alters their inhibitory effects on downstream pathways following $\mathrm{AT}_{1} \mathrm{R}$ activation [29], further confirming that the selectivity of RGS proteins to

Table 1. Characteristics of RGS proteins in the B/R4 subfamily

\begin{tabular}{lll}
\hline RGS & \multicolumn{1}{c}{ Major sites of expression } & \multicolumn{1}{c}{ Selective interaction partners (i.e. GPCRs) } \\
\hline RGS1 & B lymphocytes & Alpha2-adrenergic receptor \\
RGS2 & Widespread (especially, cardiomyocytes and VSMCs) & $\begin{array}{l}\text { Angiotensin II receptor, alpha1-adrenergic receptor, beta2-adrenergic receptor, } \\
\text { urotensin II receptor }\end{array}$ \\
RGS3 & Widespread & $\begin{array}{l}\text { Endothelin-1 receptor, angiotensin II receptor, M3 muscarinic receptors } \\
\text { M1, M2, and M5 muscarinic receptors, endothelin-1 receptor }\end{array}$ \\
RGS4 & Brain & Angiotensin II receptor, muscarinic receptor \\
RGS5 & VSMCs and pericytes & M1 muscarinic receptor \\
RGS8 & Cerebellum & CXCL12 or adenosine-sensitive receptor \\
RGS13 & B/T lymphocytes, mast cells, dendrite cells & Alpha2-adrenergic receptor \\
RGS16 & Platelets, Liver, T lymphocytes & $\mathrm{G}_{\mathrm{ai}}$ and $\mathrm{G}_{\mathrm{aq}}$ \\
RGS18 & Osteoclasts & $\mathrm{G}_{\mathrm{aq}}$ \\
\hline RGS21 & Taste bud cells & \\
\hline
\end{tabular}


specific GPCR may be determined by the properties of their N-terminals.

\section{Scaffolding proteins for regulation of RGS proteins}

The conserved RGS domain (so-called 'RGS box') is an important region where $G_{a}$ subunit is bound and GTPase activity on the subunit takes place [30]. However, the exact mechanisms underlying recognition of RGS proteins by GPCR remains uncertain. In regard to the fundamental question of how RGS proteins identify GPCR, various scaffolding proteins including homer-2, neurabin, 14-3-3, or spinophilin have been investigated. In particular, spinophilin is highly expressed in neuronal dendritic spines and brain tissues (brainstem, hypothalamus, and cerebellum) [31,32]. A fascinating hypothesis has been proposed that spinophilin acts as a linker protein connecting between RGS proteins and GPCR [33]. These investigators have examined $\mathrm{Ca}^{2+}$ signaling responses to epinephrine $(10 \& 100 \mu \mathrm{M})$ in parotid-gland ductal cells obtained from wild-type or spinophilin-deficient mice to determine the role of this scaffolding protein in the regulatory actions of RGS2 protein on GPCR. It has been found that intracellular $\mathrm{Ca}^{2+}$ signaling in oocytes is regulated by RGS2 protein bound to spinophilin that associates with the third intracellular loop of $\alpha$-adrenergic receptor [33]. Further, in neuronal dendritic spines and synapses, spinophilin is largely enriched and regulates glutamate transmission that is thought to be a key player for regulation of sympathetic outflow and autonomic control [32]. Spinophilin-deficient mice exhibit elevated blood pressure due to decreased parasympathetic activity [32] and a potentiated Ang II-mediated increase in blood pressure/heart rate [31]. As systemic knockout of spinophilin appears to cause disorders in the cardiovascular system, spinophilin may play a crucial role in vascular function. Nevertheless, there are no previous studies demonstrating function of the scaffolding protein in vasomotor responses. It will, therefore, be necessary to address the hypothesis in future studies as to whether the scaffolding protein, spinophilin, regulate activity of RGS proteins fine-tuning GPCR signaling that is crucial in cardiovascular system.

\section{ROLES OF RGS PROTEINS IN THE CARDIOVASCULAR SYSTEM}

There has been an exponential increase in studies aimed at understanding the functional significance of RGS proteins in the cardiovascular system. To clarify the physiological relevance of RGS proteins in vivo, genetic manipulation approaches such as knockout or knockdown of specific RGS proteins have been implemented (Table 2). For example RGS2 protein deficient mice have shown promise as models for investi-

Table 2. Roles of RGS2, 4, and 5 proteins in the cardiovascular system

\begin{tabular}{|c|c|c|}
\hline RGS protein & Genetic manipulation/cardiovascular diseases & Pathophysiological outcomes \\
\hline RGS2 & Knockout (1)-(3) & $\begin{array}{l}\text { (1) Exaggerated vasoconstriction and increased systemic blood pressure are attributed } \\
\text { to prolonged } \mathrm{G}_{\mathrm{q}} \mathrm{PCR} \text {-dependent signaling and reduced cGMP-mediated vasodilation } \\
\text { [35,36] } \\
\text { (2) } \mathrm{G}_{\mathrm{q}} \mathrm{PCR} \text { signaling in response to cardiac pressure overload (i.e. transverse aortic con- } \\
\text { striction, } \mathrm{TAC} \text { ) is enhanced, causing cardiac hypertrophy and early mortality; cGMP } \\
\text { hydrolytic enzyme PDE5 inhibition with sildenafil blunts TAC-mediated cardiac hyper- } \\
\text { trophy in } \mathrm{RGS} 2^{+/} \text {mice (Control), whereas antihypertrophy effect of PDE5 inhibition is } \\
\text { suppressed in RGS2 } 2^{-/} \text {animal [34] } \\
\text { (3) Excessive } \mathrm{M} 3 \text { muscarinic receptor activity occurs and induces severe atrial tachycar- } \\
\text { dia/fibrillation [65] }\end{array}$ \\
\hline RGS4 & $\begin{array}{l}\text { Pulmonary hypertension/ventricular hypertrophy/ } \\
\text { cardiomyopathy } \\
\text { Cardiac-specific RGS4 overexpression } \\
\text { Knockout }\end{array}$ & $\begin{array}{l}\text { RGS4 protein expression is upregulated and serves as a compensatory regulator to pre- } \\
\text { vent heart failure from further progression [37-42] } \\
\text { Left ventricular hypertrophy is delayed in response to pressure overload [53] } \\
\text { M2 muscarinic receptor-mediated bradycardia is augmented [66] }\end{array}$ \\
\hline RGS5 & $\begin{array}{l}\text { Hypertension/atherosclerosis } \\
\text { Overexpression } \\
\text { Knockout (1)-(3) }\end{array}$ & $\begin{array}{l}\text { mRNA levels for RGS5 protein are diminished in brain capillary of stroke-prone hyperten- } \\
\text { sion and arteriolar myocytes of atherosclerotic lesions [44,46] } \\
\text { Ventricular hypertrophy in response to TAC is attenuated [49] } \\
\text { (1) Angiotensin II (Ang II)-induced downstream signaling (e.g. MAPK activity) is potentiat- } \\
\text { ed [21] } \\
\text { (2) Hypertrophy and stiffness of arteriolar myocytes in small-sized resistance arteries are } \\
\text { profoundly increased; Ang II-mediated vasoconstriction is augmented, thereby con- } \\
\text { tributes to (gestational) hypertension [8,50] } \\
\text { (3) Ventricular hypertrophy and fibrosis in response to TAC are enhanced [49] }\end{array}$ \\
\hline
\end{tabular}


gation of the physiological function of RGS2 protein. Thus, genetic ablation of RGS2 protein led to cardiac hypertrophy following prolonged $\mathrm{G}_{\alpha \mathrm{q}}$ stimulation (i.e. increased pressure overload evoked by transverse aortic constriction surgery), suggesting that mechanical stress mediates GPCR activation and subsequent cardiac hypertrophy in an RGS2 protein-dependent manner [34]. Earlier studies by Heximer and colleagues [35] led to the hypothesis that GPCR-mediated signaling contributing to blood pressure homeostasis utilizes precisely controlled negative feedback regulatory mechanisms that involve RGS2 protein. Mice either heterozygous or exhibiting a full knockout of RGS2 protein exhibit significantly increased mean arterial pressure (MAP) and purinergic receptor (P2Y)mediated intracellular $\mathrm{Ca}^{2+}$ levels compared to controls [35]. RGS2 protein has also been shown to regulate nitric oxide (NO)-mediated vasodilation [36]. NO activates cGMP-dependent protein kinase (PKG) and subsequently leads to phosphorylation at the N-terminal of RGS2 protein that results in translocation toward plasma membrane and increased GAP activity of RGS2 protein [36].

In the heart and central nervous system RGS4 protein is the main species expressed and the transcriptional regulation of RGS4 protein appears to be altered in various pathophysiological situations. Interestingly and in contrast to other RGS proteins, pulmonary hypertension or increased pressure overload (by aortic band operation) upregulates mRNA expression for RGS4 protein in ventricular hypertrophy compared to control cardiac tissues [37-39]. Similar observations have been reported in human cardiac tissues where mRNA levels for RGS4 protein are 2-3 fold higher in cardiomyopathy compared to those in normal heart $[40,41]$. Therefore, it is likely that RGS4 protein acts as a compensatory regulator to prevent the heart failure from further progression. This is also supported by previous studies showing that $\mathrm{G}_{\mathrm{aq}}$-mediated hypertrophic signaling (i.e. myofilament arrangement and cardiomyocyte growth), in response to pressure overload, is reduced by overexpression of RGS4 protein [42].

Of the more than 30 RGS proteins, small arteries or arterioles display a strong expression of RGS5 protein [43]. Further, gene expression studies have identified that cardiovascular pathology is related to expression of RGS5 protein. In atherosclerotic lesions, mRNA levels for RGS5 protein are markedly reduced in arteriolar myocytes [44] while treatment with the anti-atherosclerotic agent, 3-hydroxy-3-methylglutaryl coenzyme A reductase inhibitor (statin), significantly upregulates expression of RGS5 protein in the aorta [45]. Moreover, transcription of RGS5 protein in the brain capillary and choroid plexus is markedly decreased in stroke-prone hypertensive rats [46]. Even though RGS5 protein is dis- pensable for arterial development during embryonic stages [14], the protein is required after birth for full arterial development [47,48]. Collectively the available data suggest that RGS5 protein may contribute to regulation of contractility or tone of arteries. Providing further support, gene expression studies show RGS5 protein to be a potent modulator of cardiovascular function. Knockout of RGS5 protein in arteriolar myocytes significantly potentiates Ang II-induced downstream signaling pathways, including enhanced activation of MAPK [21]. In cardiac tissue, pressure overload-induced cardiac remodeling is exacerbated in RGS5-deficient mice [49]. Further, in animal models with genetic deletion of RGS5 protein, resistance arteries are hypertrophied and markedly stiffened [8]. In RGS5 knockout mice, enhanced Ang II-mediated $\mathrm{Ca}^{2+}$ signaling and the resultant increase in femoral artery contraction are evident and may contribute to hypertension [8]. Aging-dependent vascular stiffness is further exacerbated in RGS5-deficient arteries [8]. In recent studies of pregnant RGS5-deficient mice, decreased expression of RGS5 protein has been implicated in causing gestational hypertension that is associated with enhanced contraction of femoral and uterine vascular beds in response to Ang II [50]. The RGS5 knockout-induced preeclampsia and gestational hypertension are ameliorated by an $\mathrm{AT}_{1} \mathrm{R}$ blocker (i.e. candesartan), suggesting that $\mathrm{AT}_{1} \mathrm{R}$ signaling-mediated blood pressure homeostasis is regulated by RGS5 protein [50].

The above studies provide information supporting a protective role for RGS proteins in the cardiovascular system. In regard to this, upregulation of RGS5 protein has been observed to attenuate $\mathrm{Ca}^{2+}$ signaling and contractility of arteries in response to administration of $\mathrm{G}_{\alpha q} \mathrm{PCR}-\mathrm{re}-$ lated vasoconstrictors, suggesting that $G_{a q}$ protein-mediated downstream signaling pathways are modulated by RGS5 protein $[8,21,38,51]$ According to previous studies [49], RGS5 overexpression opposes cardiac hypertrophy and fibrosis caused by aortic banding (i.e. increased pressure overload/mechanical stress on cardiac myocytes), which result from the RGS5 protein-dependent inhibition of MEK-ERK1/2 signaling. Additionally, cardiac-specific RGS4 protein overexpression ameliorates $G_{a q}$ protein signaling-dependent left ventricular hypertrophy under mechanical stress [52,53]. PKG-mediated phosphorylation of RGS4 protein, via application of atrial natriuretic peptide, plays an important role in guanylyl cyclase A-evoked attenuation of cardiac hypertrophy [37]. In that study, upregulation of RGS4 protein significantly abrogated heart weight, cardiomyocyte size, and cardiac hypertrophy-related gene expression in the guanylyl cyclase-A knockout animal model [37]. Taken together, it is suggested that RGS proteins mediate rapid and precise ter- 
mination of GPCR signaling pathways and reduced RGS activity causes pathophysiological function of the cardiovascular system (Fig. 3).

\section{EXERCISE TRAINING ON RGS PROTEINS}

Preeclampsia is a prevalent cardiovascular risk factor and clinical disorder which shows proteinuria and hypertension after 20 weeks of gestation [54] and affects 2-8\% of all pregnancies [55]. However, causes of preeclampsia remain incompletely understood. According to previous novel observations [50], it has been shown that expression of RGS5 protein in human myometrial arteries is significantly lower in hypertensive/preeclamptic pregnancies compared with normal pregnancies. In addition, in pregnant mice, RGS5 deletion have been shown to potentiate vascular contractility in response to Ang II and result in gestational hypertension [50]. Interestingly, it has been reported that the $G$ allele of a polymorphism in RGS2 protein gene (i.e., C114G polymorphism in rs4606) is significantly related to decreased expression of RGS2 protein and hypertension/preeclampsia [56,57]. Women with the rs4606 CG or GG genotype in spiral arteries show a higher risk for hypertension during pregnancy [58]. This study also investigated a relationship between the gene polymorphism/hypertension and exercise and suggested that regular exercise intervention may reduce the prevalence of hypertension even in women who have the rs4606 CG or GG genotype [58].

Since previous studies investigating impact of exercise training on $\mathrm{B} /$ R4 subfamily RGS proteins are lacking, G protein-coupled receptor ki-

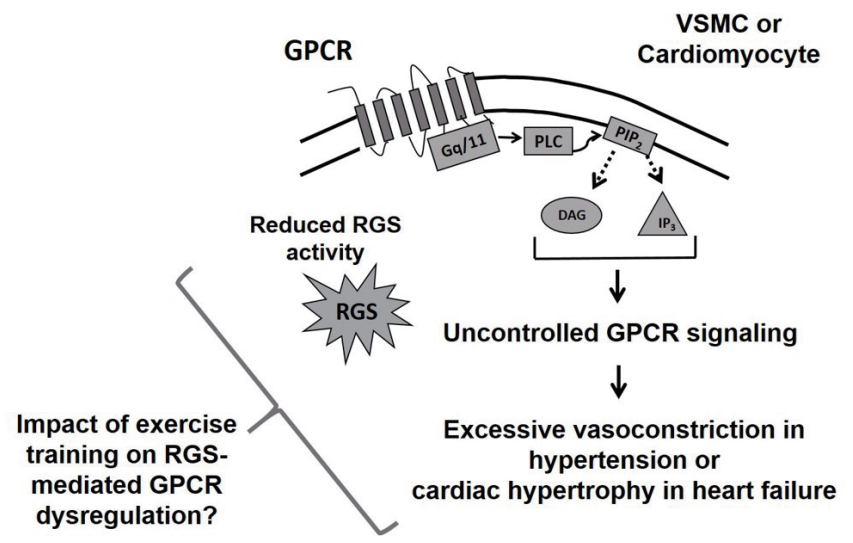

Fig. 3. Impaired activity of RGS proteins leads to GPCR dysregulation-mediated cardiovascular diseases. GPCR signaling is modulated by RGS proteins in VSMCs or cardiac myocytes of the cardiovascular system. Impaired RGS activity enhances GPCR downstream signaling and subsequently leads to exaggerated vasoconstriction or cardiac hypertrophy shown in hypertension or heart failure. DAG, diacylglycerol; $\mathrm{IP}_{3}$, inositol trisphosphate; PLC, phospholipase $\mathrm{C}_{\text {; }} \mathrm{PIP}_{2}$, phosphatidyl inositol-bisphosphate nase (GRK) that is a different subfamily of mammalian RGS proteins would be introduced in this section. GRK2 has been shown to terminate GPCR signaling by desensitizing the receptor [59]. Recent studies have demonstrated that skeletal muscle-specific GRK2 knockout substantially attenuates the force of contraction of the extensor digitorum longus muscle [60]. This genetic animal model enhanced $\beta_{2}$-adrenergic receptor $\left(\beta_{2}\right.$-AR)-mediated muscle hypertrophy by augmenting $\beta_{2}$-AR/Akt-mediated pro-hypertrophic signaling, thereby suggesting that GRK2-dependent GPCR regulation is significant for skeletal muscle function and diseases [60]. Further, desensitization of $\beta$-AR by elevated GRK2 expression has been reported in hypertension or congestive heart failure [61,62]. These pathological disorders may result from a reduction in $\beta$-AR signaling-mediated vasodilation evoked by the increased GRK2 expression [63]. In contrast, free-floating swimming program (60 min per day, 5 days per week, 10 weeks) markedly decreased blood pressure and improved insulin sensitivity in spontaneously hypertensive rats (SHR) along with reductions in GRK2 expression and activity [64]. The ameliorated insulin sensitivity shown in swimming-exercised SHR led to a significant increase in vasodilation by enhancing insulin-Akt-endothelial nitric oxide (eNOS) signaling [64]. This convincing evidence suggests that exercise-induced alteration in GRK proteins may prevent the development or progression of cardiovascular diseases.

On the basis of GRK protein studies, it is conceivable that exercise training also increases or decreases expression at transcriptional or translational level, trafficking, or activity of RGS proteins within the car-

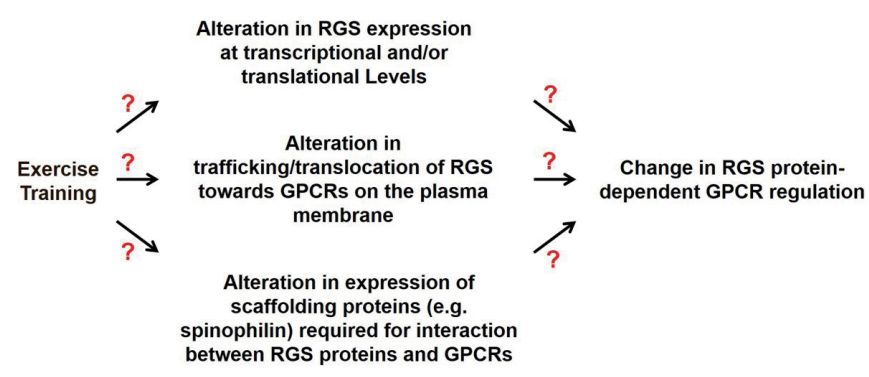

Fig. 4. Possible roles for exercise training in RGS protein-dependent GPCR regulation. It may be plausible that acute or long-term exercise intervention mediates RGS protein activity necessary for GPCR regulation by altering RGS expression, trafficking towards GPCRs, or interacting protein (i.e. scaffolding proteins) expression. While exercise program has been widely recommeded as a non-pharmacological approach/therapy to prevent or attenuate cardiovascular diseases, exact mechanisms remain elusive. In this context, further research on those fundamental questions is needed to mechanistically demonstrate how exercise training ameliorates cardipvascular comorbidities, in part, caused by impaired RGS activity-induced GPCR dysregulation. 
diovascular system (Fig. 4). For instance, since RGS2 and 5 proteins regulate the signaling of endothelin, angiotensin, P2Y, or S1P receptors in VSMCs [11], it is likely that exercise training program may diminish those receptors-mediated excessive vasoconstriction or VSMC hypertrophy, critical hallmarks in hypertension, by increasing RGS2 and 5 protein expression and/or activity. However, while RGS protein-related modulation of GPCR signaling has been well-explored, the role of exercise training in RGS protein expression and activity remains to be investigated in detail. Hence, in the field of exercise science, the impacts of exercise intervention on cardiovascular RGS proteins and GPCR downstream signaling represent fertile areas for research (Figs. 3, 4).

\section{SUMMARY}

It is well established that GPCRs play a major role in signal transduction within the cardiovascular system. Further, dysregulation of GPCRmediated downstream signaling likely leads to exaggerated or attenuated biological signaling responses that are directly associated with cardiovascular diseases. Therefore, the duration and/or magnitude of GPCR signaling is tightly controlled to sustain appropriate physiological functions in the cardiovascular system. As outlined earlier, RGS proteins hydrolyze GTP on the active a subunit of $G$ protein and fine-tune $G$ protein-mediated signaling. Thus, RGS proteins play an important role as negative feedback regulators and impaired RGS protein regulation has been strongly related to cardiovascular diseases. As exercise training has been demonstrated to reduce risk for cardiovascular disorders, it is therefore suggested that it will be valuable to explore the contribution of exercise training to RGS protein-mediated regulation of GPCR signaling within the cardiovascular system.

\section{ACKNOWLEDGEMENT}

We cordially thank Dr. Michael Hill, University of Missouri-Columbia, for constructive review of the manuscript prior to submission.

\section{REFERENCES}

1. Brady AE, Limbird LE. G protein-coupled receptor interacting proteins: emerging roles in localization and signal transduction. Cellular Signalling 2002;14(4):297-309.

2. Salon JA, Lodowski DT, Palczewski K. The significance of G protein- coupled receptor crystallography for drug discovery. Pharmacological Reviews 2011;63(4):901-937.

3. Schoneberg T, Schulz A, Biebermann H, Hermsdorf T, Rompler H, et al. Mutant G-protein-coupled receptors as a cause of human diseases. Pharmacology \& Therapeutics 2004;104(3):173-206.

4. Hendriks-Balk MC, Peters SL, Michel MC, Alewijnse AE. Regulation of $G$ protein-coupled receptor signalling: focus on the cardiovascular system and regulator of $\mathrm{G}$ protein signalling proteins. European Journal of Pharmacology 2008;585(2-3):278-291.

5. Insel PA, Tang CM, Hahntow I, Michel MC. Impact of GPCRs in clinical medicine: monogenic diseases, genetic variants and drug targets. Biochimica Biophysica Acta 2007;1768(4):994-1005.

6. Rosskopf D, Michel MC. Pharmacogenomics of G protein-coupled receptor ligands in cardiovascular medicine. Pharmacological Reviews 2008;60(4):513-535.

7. Brinks HL, Eckhart AD. Regulation of GPCR signaling in hypertension. Biochimica Biophysica Acta 2010;1802(12):1268-1275.

8. Holobotovskyy V, Manzur M, Tare M, Burchell J, Bolitho E, et al. Regulator of G-protein signaling 5 controls blood pressure homeostasis and vessel wall remodeling. Circulation Research 2013;112(5):781791.

9. Hollinger S, Hepler JR. Cellular regulation of RGS proteins: modulators and integrators of $\mathrm{G}$ protein signaling. Pharmacological Reviews 2002;54(3):527-559.

10. Ross EM, Wilkie TM. GTPase-activating proteins for heterotrimeric G proteins: regulators of $\mathrm{G}$ protein signaling (RGS) and RGS-like proteins. Annual Review of Biochemistry 2000;69:795-827.

11. Gu S, Cifelli C, Wang S, Heximer SP. RGS proteins: identifying new GAPs in the understanding of blood pressure regulation and cardiovascular function. Clinical Science (London) 2009;116(5):391-399.

12. Abramow-Newerly M, Roy AA, Nunn C, Chidiac P. RGS proteins have a signalling complex: interactions between RGS proteins and GPCRs, effectors, and auxiliary proteins. Cellular Signalling 2006; 18(5):579-591.

13. Bansal G, Druey KM, Xie Z. R4 RGS proteins: regulation of G-protein signaling and beyond. Pharmacology \& Therapeutics 2007;116(3):473495.

14. Ganss R. Keeping the Balance Right: Regulator of G Protein Signaling 5 in Vascular Physiology and Pathology. Progress Molecular Biology and Translational Science 2015;133:93-121.

15. Bernstein LS, Grillo AA, Loranger SS, Linder ME. RGS4 binds to 
membranes through an amphipathic alpha -helix. The Journal of Biological Chemistry 2000;275(24):18520-18526.

16. Chen C, Seow KT, Guo K, Yaw LP, Lin SC. The membrane association domain of RGS16 contains unique amphipathic features that are conserved in RGS4 and RGS5. The Journal of Biological Chemistry 1999; 274(28):19799-19806.

17. Neitzel KL, Hepler JR. Cellular mechanisms that determine selective RGS protein regulation of $G$ protein-coupled receptor signaling. Seminars in Cell \& Developmental Biology 2006;17(3):383-389.

18. Cho H, Harrison K, Schwartz O, Kehrl JH. The aorta and heart differentially express RGS (regulators of G-protein signalling) proteins that selectively regulate sphingosine 1-phosphate, angiotensin II and endothelin-1 signalling. Biochemical Journal 2003;371(Pt 3):973-980.

19. Xu X, Zeng W, Popov S, Berman DM, Davignon I, et al. RGS proteins determine signaling specificity of Gq-coupled receptors. The Journal of Biological Chemistry 1999;274(6):3549-3556.

20. Adebiyi A. RGS2 regulates urotensin II-induced intracellular Ca2+elevation and contraction in glomerular mesangial cells. Journal of Cellular Physiology 2014;229(4):502-511.

21. Wang Q, Liu M, Mullah B, Siderovski DP, Neubig RR. Receptor-selective effects of endogenous RGS3 and RGS5 to regulate mitogen-activated protein kinase activation in rat vascular smooth muscle cells. The Journal of Biological Chemistry 2002;277(28):24949-24958.

22. Hoffmann M, Ward RJ, Cavalli A, Carr IC, Milligan G. Differential capacities of the RGS1, RGS16 and RGS-GAIP regulators of G protein signaling to enhance alpha2A-adrenoreceptor agonist-stimulated GTPase activity of G(o1)alpha. Journal of Neurochemistry 2001;78(4): 797-806.

23. Itoh M, Nagatomo K, Kubo Y, Saitoh O. Alternative splicing of RGS8 gene changes the binding property to the M1 muscarinic receptor to confer receptor type-specific Gq regulation. Journal of Neurochemistry 2006;99(6):1505-1516.

24. Bansal G, DiVietro JA, Kuehn HS, Rao S, Nocka KH,et al. RGS13 controls g protein-coupled receptor-evoked responses of human mast cells. The Journal of Immunology 2008;181(11):7882-7890.

25. Iwai K, Koike M, Ohshima S, Miyatake K, Uchiyama Y, et al. RGS18 acts as a negative regulator of osteoclastogenesis by modulating the acid-sensing OGR1/NFAT signaling pathway. Journal of Bone and Mineral Research 2007;22(10):1612-1620.

26. von Buchholtz L, Elischer A, Tareilus E, Gouka R, Kaiser C, et al. RGS21 is a novel regulator of G protein signalling selectively expressed in subpopulations of taste bud cells. European Journal of Neuroscience 2004;19(6):1535-1544.

27. Zeng W, Xu X, Popov S, Mukhopadhyay S, Chidiac P, et al. The N-terminal domain of RGS4 confers receptor-selective inhibition of G protein signaling. The Journal of Biological Chemistry 1998;273(52): 34687-34690.

28. Zhou J, Moroi K, Nishiyama M, Usui H, Seki N, et al. Characterization of RGS5 in regulation of G protein-coupled receptor signaling. Life Sciences 2001;68(13):1457-1469.

29. Matsuzaki N, Nishiyama M, Song D, Moroi K, Kimura S. Potent and selective inhibition of angiotensin AT1 receptor signaling by RGS2: roles of its N-terminal domain. Cellular Signalling 2011;23(6):10411049.

30. Sjogren B, Neubig RR. Thinking outside of the "RGS box": new approaches to therapeutic targeting of regulators of $G$ protein signaling. Molecular Pharmacology 2010;78(4):550-557.

31. da Costa Goncalves AC, Fontes MA, Klussmann E, Qadri F, Janke J, et al. Spinophilin regulates central angiotensin II-mediated effect on blood pressure. Journal of Molecular Medicine (Berlin) 2011;89(12):1219-1229.

32. da Costa-Goncalves AC, Tank J, Plehm R, Diedrich A, Todiras M, et al. Role of the multidomain protein spinophilin in blood pressure and cardiac function regulation. Hypertension 2008;52(4):702-707.

33. Wang X, Zeng W, Soyombo AA, Tang W, Ross EM, et al. Spinophilin regulates $\mathrm{Ca} 2+$ signalling by binding the $\mathrm{N}$-terminal domain of RGS2 and the third intracellular loop of G-protein-coupled receptors. Nature Cell Biology 2005;7(4):405-411.

34. Takimoto E, Koitabashi N, Hsu S, Ketner EA, Zhang M, et al. Regulator of $\mathrm{G}$ protein signaling 2 mediates cardiac compensation to pressure overload and antihypertrophic effects of PDE5 inhibition in mice. Journal of Clinical Investigation 2009;119(2):408-420.

35. Heximer SP, Knutsen RH, Sun X, Kaltenbronn KM, Rhee MH, et al. Hypertension and prolonged vasoconstrictor signaling in RGS2-deficient mice. Journal of Clinical Investigation 2003;111(4):445-452.

36. Tang KM, Wang GR, Lu P, Karas RH, Aronovitz M, et al. Regulator of G-protein signaling-2 mediates vascular smooth muscle relaxation and blood pressure. Nature Medicine 2003;9(12):1506-1512.

37. Tokudome T, Kishimoto I, Horio T, Arai Y, Schwenke DO, et al. Regulator of G-protein signaling subtype 4 mediates antihypertrophic effect of locally secreted natriuretic peptides in the heart. Circulation 2008;117(18):2329-2339.

38. Wang X, Adams LD, Pabon LM, Mahoney WM Jr, Beaudry D, et al. 
RGS5, RGS4, and RGS2 expression and aortic contractibility are dynamically co-regulated during aortic banding-induced hypertrophy. Journal of Molecular and Cellular Cardiology 2008;44(3):539-550.

39. Zhang S, Watson N, Zahner J, Rottman JN, Blumer KJ, et al. RGS3 and RGS4 are GTPase activating proteins in the heart. Journal of Molecular and Cellular Cardiology 1998;30(2):269-276.

40. Mittmann C, Chung CH, Hoppner G, Michalek C, Nose M, et al. Expression of ten RGS proteins in human myocardium: functional characterization of an upregulation of RGS4 in heart failure. Cardiovascular Research 2002;55(4):778-786.

41. Owen VJ, Burton PB, Mullen AJ, Birks EJ, Barton P, et al. Expression of RGS3, RGS4 and Gi alpha 2 in acutely failing donor hearts and end-stage heart failure. European Heart Journal 2001;22(12):10151020.

42. Tamirisa P, Blumer KJ, Muslin AJ. RGS4 inhibits G-protein signaling in cardiomyocytes. Circulation 1999;99(3):441-447.

43. Adams LD, Geary RL, McManus B, Schwartz SM. A comparison of aorta and vena cava medial message expression by cDNA array analysis identifies a set of 68 consistently differentially expressed genes, all in aortic media. Circulation Research 2000;87(7):623-631.

44. Li J, Adams LD, Wang X, Pabon L, Schwartz SM, et al. Regulator of G protein signaling 5 marks peripheral arterial smooth muscle cells and is downregulated in atherosclerotic plaque. Journal of Vascular Surgery 2004;40(3):519-528.

45. Liu SL, Li YH, Shi GY, Jiang MJ, Chang JH, et al. The effect of statin on the aortic gene expression profiling. Internation Journal of Cardiology 2007;114(1):71-77.

46. Kirsch T, Wellner M, Luft FC, Haller H, Lippoldt A. Altered gene expression in cerebral capillaries of stroke-prone spontaneously hypertensive rats. Brain Research 2001;910(1-2):106-115.

47. Bondjers C, Kalen M, Hellstrom M, Scheidl SJ, Abramsson A, et al. Transcription profiling of platelet-derived growth factor-B-deficient mouse embryos identifies RGS5 as a novel marker for pericytes and vascular smooth muscle cells. American Journal of Pathology 2003; 162(3):721-729.

48. Cho H, Kozasa T, Bondjers C, Betsholtz C, Kehrl JH. Pericyte-specific expression of Rgs5: implications for PDGF and EDG receptor signaling during vascular maturation. The FASEB Journal 2003;17(3):440442.

49. Li H, He C, Feng J, Zhang Y, Tang Q, et al. Regulator of G protein signaling 5 protects against cardiac hypertrophy and fibrosis during bio- mechanical stress of pressure overload. Proceedings of the National Academy of Sciences USA 2010;107(31):13818-13823.

50. Holobotovskyy V, Chong YS, Burchell J, He B, Phillips M, et al. Regulator of $\mathrm{G}$ protein signaling 5 is a determinant of gestational hypertension and preeclampsia. Science Translational Medicine 2015;7(290): 290ra88

51. Yang Z, Balenga N, Cooper PR, Damera G, Edwards R, et al. Regulator of G-protein signaling-5 inhibits bronchial smooth muscle contraction in severe asthma. American Journal of Respiratory Cell and Molecular Biology 2012;46(6):823-832.

52. Rogers JH, Tamirisa P, Kovacs A, Weinheimer C, Courtois M, et al RGS4 causes increased mortality and reduced cardiac hypertrophy in response to pressure overload. Journal of Clinical Investigation 1999; 104(5):567-576.

53. Rogers JH, Tsirka A, Kovacs A, Blumer KJ, Dorn GW, et al. RGS4 reduces contractile dysfunction and hypertrophic gene induction in Galpha q overexpressing mice. Journal of Molecular and Cellular Cardiology 2001;33(2):209-218.

54. Practice ACoO. ACOG practice bulletin. Diagnosis and management of preeclampsia and eclampsia. Number 33, January 2002. American College of Obstetricians and Gynecologists. International Journal of Gynaecology \& Obstetrics 2002;77(1):67-75.

55. Steegers EA, von Dadelszen P, Duvekot JJ, Pijnenborg R. Pre-eclampsia. Lancet 2010;376(9741):631-644.

56. Kvehaugen AS, Melien O, Holmen OL, Laivuori H, Oian P, et al. Single nucleotide polymorphisms in $\mathrm{G}$ protein signaling pathway genes in preeclampsia. Hypertension 2013;61(3):655-661.

57. Semplicini A, Lenzini L, Sartori M, Papparella I, Calo LA, et al. Reduced expression of regulator of G-protein signaling 2 (RGS2) in hypertensive patients increases calcium mobilization and ERK1/2 phosphorylation induced by angiotensin II. Journal of Hypertension 2006; 24(6):1115-1124.

58. Kvehaugen AS, Melien O, Holmen OL, Laivuori H, Dechend R, et al. Hypertension after preeclampsia and relation to the $\mathrm{C} 1114 \mathrm{G}$ polymorphism (rs4606) in RGS2: data from the Norwegian HUNT2 study. BMC Medical Genetics 2014;15:28.

59. Seibold A, Williams B, Huang ZF, Friedman J, Moore RH, et al. Localization of the sites mediating desensitization of the beta(2)-adrenergic receptor by the GRK pathway. Molecular Pharmacology 2000;58(5): 1162-1173.

60. Woodall BP, Woodall MC, Luongo TS, Grisanti LA, Tilley DG, et al. 
Skeletal Muscle-specific G Protein-coupled Receptor Kinase 2 Ablation Alters Isolated Skeletal Muscle Mechanics and Enhances Clenbuterol-stimulated Hypertrophy. The Journal of Biological Chemistry 2016;291(42):21913-21924.

61. de Lucia C, Femminella GD, Gambino G, Pagano G, Allocca E, et al. Adrenal adrenoceptors in heart failure. Frontiers in Physiology 2014;5: 246.

62. Ryan JJ, Archer SL. The right ventricle in pulmonary arterial hypertension: disorders of metabolism, angiogenesis and adrenergic signaling in right ventricular failure. Circulation Research 2014;115(1):176-188.

63. Santulli G, Trimarco B, Iaccarino G. G-protein-coupled receptor kinase 2 and hypertension: molecular insights and pathophysiological mechanisms. High Blood Pressure \& Cardiovascular Prevention 2013;
20(1):5-12.

64. Xing W, Li Y, Zhang H, Mi C, Hou Z, et al. Improvement of vascular insulin sensitivity by downregulation of GRK2 mediates exercise-induced alleviation of hypertension in spontaneously hypertensive rats. American Journal of Physiology Heart and Circulatory Physiology 2013;305(8):H1111-1119.

65. Tuomi JM, Chidiac P, Jones DL. Evidence for enhanced M3 muscarinic receptor function and sensitivity to atrial arrhythmia in the RGS2 -deficient mouse. American Journal of Physiology Heart and Circulatory Physiology 2010;298(2):H554-561.

66. Grillet N, Pattyn A, Contet C, Kieffer BL, Goridis C, et al. Generation and characterization of Rgs4 mutant mice. Molecular and Cellular Biology 2005;25(10):4221-4228. 